\title{
Productive Resistance within the Korean Public Sector: Exploring Organisational Culture
}

\author{
Sunghee Park $^{1} \cdot$ Neil Lunt ${ }^{1}$
}

Published online: 1 February 2017

(C) The Author(s) 2017. This article is published with open access at Springerlink.com

\begin{abstract}
The article examines how South Korean civil servants responded to the introduction of pay for performance. Drawing upon 31 in-depth interviews with career civil servants, it identifies what became known as $1 / \mathrm{n}$, a form of 'discreet resistance' that emerged and evolved. The analytical framework allows productive resistance to be seen as ebbing and flowing during organisational change that sees institutionalisation, deinstitutionalisation and re-institutionalisation. In understanding the cultural context of organisational resistance the contribution is three-fold. First, a nuanced definition and understanding of productive resistance. Second, it argues that productive resistance must be seen as part of a process that does not simply reflect 'offer and counter-offer' within the change management process. Thirdly, it identifies differences within groups and sub-cultures concerning commitment towards resistance and how these fissures contribute towards change as new interpretive schemes and justifications are presented in light of policy reformulations.
\end{abstract}

Keywords Culture Productive resistance Change management $\cdot$ South Korea Confucian

\section{Introduction}

This article discusses resistance that arose as a response towards the introduction of Performance Related Pay (P4P) within the Korean public sector. A gap in the organisational literature is to better understand how resistance can influence workplace change (see Courpasson et al. 2012), and arguably the ways in which this may occur across diverse cultural contexts - Confucian as well as Western. Exploring opposition to change is a valuable exercise (Krantz 1999; Starr 2011; Burnes 2015), including

Neil Lunt

neil.lunt@york.ac.uk

1 Department of Social Policy and Social Work, University of York, Heslington, York YO10 5DD, UK 
understanding how policy recipients respond to policy mandates (McDermott et al. 2013, s112). The article presents public servants' reactions to change as a 'discreet' form of resistance (Fronda 2008):

not explicit resistance (as in conventional revolts or strikes), or a mental pulling-out from the professional sphere (as in withdrawal), but a form of "deviance" which complies with the letter of the law but discreetly resists its spirit (Fronda 2008, 591).

We explore whether such discreet resistance had distinctive productive properties. The notion of 'productive resistance' has developed within the organisational studies literature (Krantz 1999; Ford et al. 2008; Starr 2011; McDermott et al. 2013) to counter resistance being framed solely as a blockage or counter-rational response to change. However, the concept of productive resistance remains somewhat ambiguous, and given this lack of clarity a key task is to sharpen its meanings and situate it within distinct organisational culture.

By focusing attention on the 'resistance process' (van Dijk and van Dick 2009, 144) there is potential to understand how productive resistance is integrated into organisational change processes and contributes towards resolution (Erwin and Garman 2010). The motivational roots of productive resistance will be seen as located not in micro-politics but in existing organisational culture, with responses less about fear or loss by factions and more related to established social relations. There is also a methodological imperative underpinning the discussion if: 'Resistance has to be judged on its merits and from multiple perspectives, and the activities of those who see themselves as resistant subjects must be factored into this analysis' (Thomas and Hardy 2011, 330). However, as will be discussed, not all subject will identify as 'resistant subjects' and actors may have relatively little intention behind actions that shape improvements because their emphasis in on reproducing day-to-day routines. The paper is structured in four parts. First a brief review of the concepts and literature relating to reaction to change, resistance and, in particular, productive resistance. Second, overview of the organisational case study context and research methods adopted. Third, findings, followed fourth, by a discussion of what the case contributes towards understanding positive resistance.

\section{Reactions to Change and Productive Resistance}

Understanding reactions to change initiatives remains a core concern of change management. Given organisations are inherently peopled environments with inherited interests, attitudes, egos and expectations, changes in organisational practice, process and system may evoke distinct emotional and behavioural responses - including shock, surprise, resigned acceptance, even enthusiastic support. There is also a likelihood of opposition or resistance to change and this has been a focus within classical, conventional and critical literatures (Coch and French 1948; Watson 1971; Strickland 1998; Hughes 2010; Pietese et al. 2012). Since Lewin's writing on resistance and force-field analysis, divergent literatures have mushroomed across psychology, organisational studies and political analysis (Patalano 2011; Burnes 2015). Lines (2004, 198) defines resistance as 'behaviours that are acted out by change recipients in order to slow down or terminate an intended organisational change'. These may arise at the individual, 
group or organisational level. Carr and Brower $(2000,114)$ see bureaucratic resistance as 'action or intentional inaction that defies, opposes or sidesteps the rules, roles or routines of the organization'. Reluctance to accept a change has many guises, including overt behaviours (strikes, working to rule and lower productivity), and more covert and passive behaviours to frustrate - such as lateness, absence and reduced engagement and effort (Ackroyd and Thompson 1999; Fronda 2008).

The roots of resistance are identified as lying in various settings: psychology, systems, institutional and organisational cultures (Graetz et al. 2002, 260 cited in Hughes 2010, 167-8). For Kotter and Schlesinger (1979) resistance arises from selfinterest, misunderstanding, different assessments, and low tolerance for change. Conventional change management and organisational development practice focus on how resistance should be managed and the removal of barriers (see Linstead et al. 2004, 447 for discussion of this point). Focussing on surface resistance risks seeing only one face of power, ignoring that some issues never make it to be a focus of change, and how prevailing structural interests operate around organisations and policy (Lukes 1974). Sturdy and Grey (2003) point to a 'pro-change bias' in the literature and organisational development is awash with techniques and strategies to remove potential blocks (Burnes 2009; also Kotter and Schlesinger 1979; Cunningham and Kempling 2009). This allows a widely accepted mental model that underpins organisational behaviour, 'the idea that there is resistance to change and that managers must overcome it' (Dent and Goldberg 1999, 25). To circumvent staff resistance there is reductionism focused on communication, education and participation.

Some writers have argued that resistance is a self-serving and potentially selffulfilling label, that change agents attribute in seeking to rationalise the response of recipients to change agendas (Ford et al. 2008). There has been an attempt to acknowledge that resistance is not necessarily a negative response and that rather than resistance always viewed as a pejorative, 'productive resistance' may constitute a bulwark against rapid and ill-thought out change (Fronda 2008). Piderit (2000, 783) points to positive intentions behind negative responses to change being ignored and that: 'what some may perceive as disrespectful or unfounded opposition might also be motivated by individuals' ethical principles or by their desires to protect the organization's best interests' (2000, 785). Opportunism is not therefore synonymous with self-interested behaviour (Carr and Brower 2000). For some, the term 'resistance to change' is beyond rehabilitation (Dent and Goldberg 1999), others focus on reconstructing resistance (Ford et al. 2008), which includes seeing it as a multidimensional concept (Piderit 2000, 789) and acknowledging how ambivalence and cognitive (beliefs), emotional, and intentional (behaviour) dimensions complicate our understanding of resistance and change.

Most usage of 'productive' (and similarly 'thoughtful' or 'facilitative' resistance) (see Thomas and Hardy 2011) has been within the organisational change and ICT implementation literature (McKay et al. 2012; Ferneley and Sobreperez 2006). However precise meaning and understanding remains unclear. This has led to suggestions that the term is 'something of an oxymoron in which 'real' resistance can scarcely be viewed as positive, and positively intended feedback in order to improve a situation should not be regarded as resistance' (McKay et al. 2012, 2). The term also risks establishing a binary - productive versus unproductive resistance - and questions arise about who decides whether and whose behaviours are either one or the other (Ford et al. 2008; McKay et al. 2012; Thomas and Hardy 2011). Attention to how 'researchers have largely overlooked 
the potentially positive intentions that may motivate negative responses to change' (Piderit 2000, 783), highlights individuals and groups of individuals as change recipients who behave in particular 'intentioned' ways. Notwithstanding calls to view resistance as multidimensional - for example, Piderit's distinctions of emotional, cognitive, and intentional - productive resistance risks assuming an overly purposeful agency. Thus individuals and groups resist and make suggestions in the form of counter-proposals to provide better understandings and additional options and solutions to what is currently on the table (see Binci et al. 2012). Positive resistance becomes somewhat transactional and strategic and can soon lead to change management advice that: 'Change resisters should go a bit further and demand that the person proposing the change prove that what he or she is proposing is best for the company' (de Jager 2001, 25). Nor is productive resistance simply apathy - a more nuanced understanding that reflects organisational realities and institutional consideration will show that productive outcomes may be neither clearly intentioned nor simply the result of apathy.

People and groups are embedded in larger structures and cultures and adopting an institutionalist framework focuses on the informal institutions and cognitive repertoires upon which they draw - orientating us towards habits, routines and norms (Nielsen 2001; Scott 2001; Meyer 2007). Whilst allowing agency the freedom to deliberate (and be not simply a rule follower or some version of crude economic man) it is key to explore how participants are influenced, transformed and completed by informal structures (Thoenig 2011). Discussion will focus on what is the appropriate response (rather than simply utility maximisation) and how this shifts in the interpretation of moral codes and frames of reference (Bell 2002). Social norms are internalised through a range of processes - recruitment and work practices and these are subject to change: "Identity is not fixed but constructed in different ways over time as a result of such factors as career progression, organizational setting, and the nature of work" (Thomas and Hardy 2011, 325). The account ensures we do not leave individuals without history, society or culture, or alternatively 'drain[s] such relationships of their active, subjective dimensions and their cultural contents and meanings (Emirbeyer and Goodwin 1994, 1428). The approach acknowledges that micro-interactions take place within an existing social structure and are shaped by that structure (Lloyd 1986, 188). But the account avoids over-playing meaning and communication whereby social actors reproduce routines but where seemingly their meaning-creating capabilities never actually accomplish an action, transcend or transform a situation (Campbell 1996, 151; also Layder 1994).

Given such accounts this article provides a more detailed illustration of productive resistance within organisational culture and change (Courpasson et al. 2012). It offers an in-depth, inductive qualitative examination, valuable because studies are typically self-report survey studies across organisations (Erwin and Garman 2010; Thomas and Hardy 2011). The contribution is two-fold: first situating productive resistance within the ebb and flow of the durée of the organisational change (rather than simply an episode). Second, it moves beyond seeing resistance as an individual trait (see, Burnes 2015), to examining interventions at individual, group, and organisational levels and how they challenge individual identity but also group norms and values within organisations (Erwin and Garman 2010). Thus, the focus is on examining 'how resistance to change evolves over time, is influenced by change interventions, the sequence of interventions, and how it operates at an individual, group, and organizational levels' (Erwin and Garman 2010, 50). 


\section{Research Setting}

Research was undertaken in the Korean civil service on the general services' implementation of Pay for Performance schemes. In-depth interviews were conducted with public servants in order to focus on processes, behaviours, attitudes and meanings of the policy change (Creswell 2007; Denzin and Lincoln 2008, 14). Korean society (and its civil service) is a valuable setting to explore productive resistance given society is strongly influenced by Confucian ethics, and has been subject to strong NPM reforms. The case also highlights institutionalisation and de-institutionalisation, not simply focussing on the persistence of phenomena to the neglect of how change happens (Dacin et al. 2002)

Within Korean society five basic principles together contribute to maintaining a traditional hierarchy system of family, community and administration (Song 1990; Sagong 1993). In particular, respect for elders plays an important role and impacts on the seniority system in Korean society, indirectly recommending that seniority be favoured in promotion, evaluation and performance appraisal. Second, 'respect for honour' directly influences civil service motivation and identity, with civil service seen as high in the traditional social class hierarchy (Ko 2002, 376; also Frederickson 2002). Third, collectivism influences all levels of group and community social interaction. Fourth, the Confucian ethic elevates family, and this concept of family expands to groups, organisations and communities (Yoon 2001). Leadership is strongly transactional, incorporating top-down control with paternalistic care for employees' personal and family needs (cf McCarthy et al. 2008). Finally, personal connections (blood networks, regional networks and school networks) are fundamental to relationships (Kim and Hoppe-Graff 2001; Sung 2003; Jung 2007). In summary, Koreans are traditionally collectivistic in outlook, emphasise homogeneity and when measured on performance orientation, institutional collectivism, and in-group collectivism Confucian countries score highly, reflecting a results-driven orientation that prefers group work over individual goals (Hofstede 2001; Northouse 2012). Confucianism shapes family relations and practices, influences education and examinations (Kim 2009) and is embedded within institutional structures. It is simply the "way things are done around here' (Deal and Kennedy 1982).

The traditional career-based civil service system is strongly derivative of these Confucian values - seen in the rigid examinations entry system and prevailing sense of duty (Frederickson 2002). Korean civil servants working in 'career service' pass an entrance examination and are expected to make a life-long commitment to the service with legal status and job security guaranteed by law. General civil servants within the administrative and research fields are employed within eight strong vertical classifications and a pyramid hierarchy (Senior Civil Service, and Grades 3-9).

\section{Qualitative Study Methods}

The research utilised personal networks and past work experience for opportunities to contact relevant officials (see Taylor 2011). A sample of 31 was drawn from across four ministries chosen to give a range with interviewee selection balanced (using a matrix to consider characteristics being met and missing) in terms of rank, method of entry, length of employment and gender (see Tables 1 and 2 below). The gender imbalance of 
Park S., Lunt N.

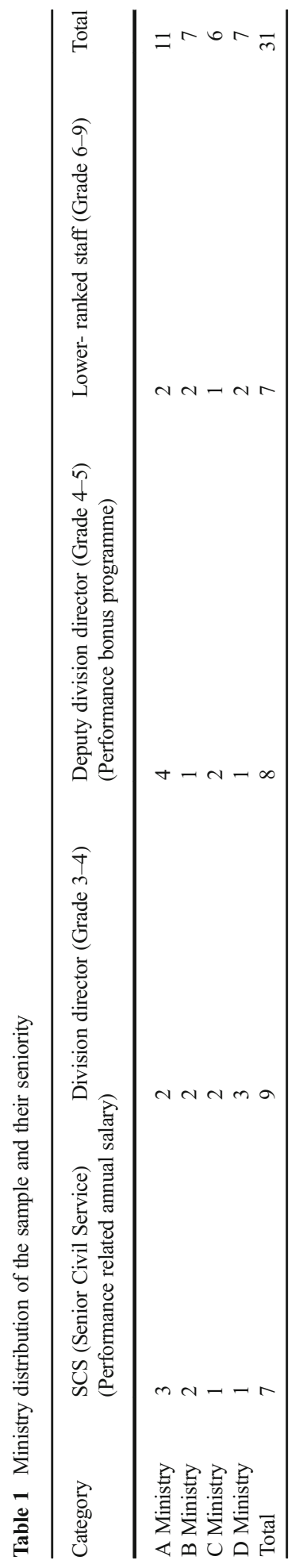




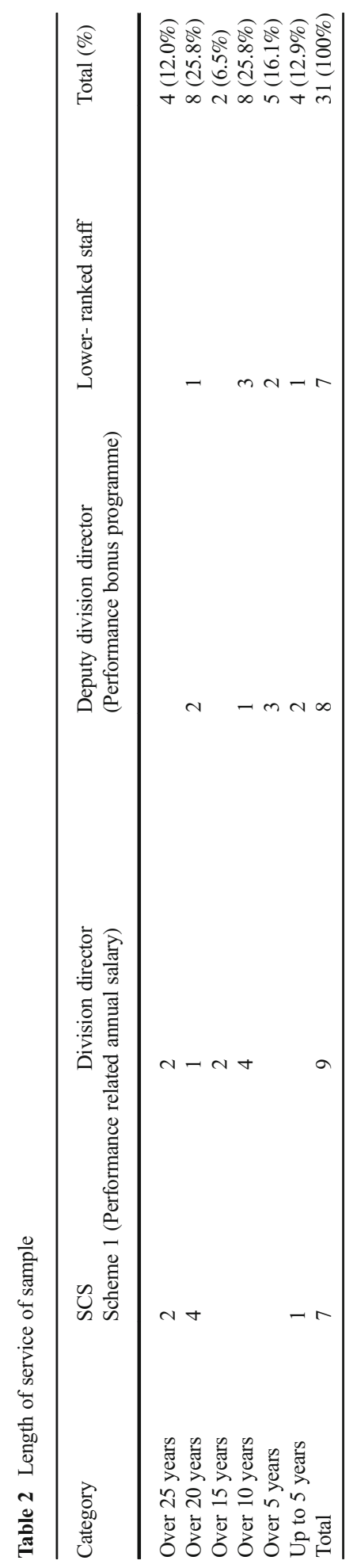


the sample ( 7 out of 31 participants were female) means this study has not introduced a gender dimension to analysis - an acknowledged limitation.

The researcher was a civil servant on study leave from the Korean public service raising issues of insider status. In the South Korean context insider/outsider is not reducible to a simple binary, but more complicated to reflect Confucian orderings and multiple status/identities (Kim 2012; see also Mercer 2006). Within projects researchers may not be uniformly insiders but also embrace identities of stranger, visitor or initiate (Flick 1998, 59-61). Arguably, personal networks helped obtain richer data, and numerous respondents expressed the view that prior connections facilitated a smoother discussion. By contrast, it was sometimes more difficult to build rapport with respondents recruited via a process of recommendation - similar obstacles to undertaking elite interviews are identified elsewhere (e.g. Harvey 2011). The research study gained ethics approval from an institutional ethics committee, with attention paid to confidentiality, informed consent, anonymity, insider status, and data storage. Interviews were conducted, transcribed and analysed in Korean, and final analysis was translated into English. The data was handled using the 'framework method' of thematic analysis (Ritchie and Spencer 1993; Ritchie and Lewis 2003; Richards 2009). This allowed a search for conceptual definitions, typologies, classifications, form and nature (process, system, attitudes, behaviours), and explanations (Miles and Huberman 1994).

Within East Asian organisations methodological challenges exist to conducting research, including difficulties of gaining access to steep hierarchical organisations, the lack of a critical social science tradition, and the strong preference for quantitative methodologies. The fieldwork underpinning this article navigated such sensitivities and examines evolution of reactions, including emergent forms of professional and managerial responses. The ability to look retrospectively at the change offers insights for understanding shifts in organisational culture, and to grasp the interactions of the professional cultural codes and the external policy drivers (see Sandelowski 1999). Inevitably qualitative research of events that occurred some years earlier bring significant limitations of recall and also post-hoc rationalisation and these should be acknowledged (Morse et al. 2008). Longitudinal work would allow research to further explore conceptual and theoretical insights but was not available within this study. As such, data here is presented in a way that observes a precautionary principle - avoiding overstepping the boundaries of what may reasonably be inferred from the data alongside its triangulation with wider literature and documents.

\section{Organisational Culture and Reactions to P4P}

The performance-based pay system saw two types of programmes introduced. First, those at senior grade (division director grade and above) receive performance related pay that accrues to the following year's basic salary. Such senior managers are appraised with four grades, and only the upper $20 \%$ of employees can be given an Excellent grade, whilst the bottom $10 \%$ are ineligible for P4P. The grades are determined mainly by performance appraisal (including 360 degree feedback) based on a Performance Agreement. Performance pay is paid once a year spread out evenly into monthly salary, and added to the base pay of the following year. Second, mid and lower level managers (Grade 4 non-division director, Grade 5 and below) have a Performance 
Bonus Programme with a single payment. This Performance Bonus Programme has the same categories of P4P grades and a forced ratio of ranking allocation (lowest $10 \%$ denied a bonus) and grades also determined mainly by performance appraisal. The reward is paid as a lump sum bonus and the amount depends on grade.

The policy mandate for P4P in the early 2000s was top-down and focused on vision and implementation in a classic command and control style (Jenkins 1978; Sturdy and Grey 2003; Burnes 2009; Hughes 2010). Its introduction into both the wider Korean public service and the central civil service evoked distinct responses. Nearly 80,000 teachers from a trade union of teachers (jungyojo) responded by returning their performance dividend of 28 billion Korean won to the authorities (Kim 2004, 527). In comparison the response of central civil servants was more passive, but not apathetic, and in some ministries a behavioural response involved performance bonuses being collected and redistributed equally by staff among peer groups within the same rank (the practice of ' $1 / \mathrm{n}$ ') (Im 2003).

The narrative of the rise, emergence and fall of $1 / \mathrm{n}$ is usefully presented in three parts to illuminate the complexities of productive resistance. Thus we examine emergence of $1 / \mathrm{n}$ (its institutionalisation); the decline of $1 / \mathrm{n}$ (what is in effect de-institutionalisation); and the reintroduction of seniority-based principles (the re-institutionalisation of previous values).

\section{1) The emergence of $1 / \mathrm{n}$ practice}

The practice of $1 / \mathrm{n}$ was prevalent with the first distribution of performance rewards around 2001. Given nine interviewees (from 31) were civil servants for less than 10 years they could not have participated in $1 / n$ when the practice was at its height. Indeed the sample falls into broad groups: those that participated; those that did not; and those that could not because they entered public service after the decline of the practice. Thus, almost half of the eligible sample took part in $1 / \mathrm{n}$ and additionally the whole sample expressed opinions and insights on the $1 / \mathrm{n}$ process.

For many respondents $1 / \mathrm{n}$ was an expression of opposition to the newly introduced individual incentive scheme. However, this opposition was less an individual trait of resistance than an expression of group and sub-organisational loyalty. Concerns that $\mathrm{P} 4 \mathrm{P}$ would lead to disharmony led to a collective response shaped by the organisational context. More overt opposition was problematic on two grounds: the prevailing ideational assumption of obedience and lack of dissent tradition in public service; second, structurally there was absence of any clear vehicle or strategy to harness opposition. At the time of P4P's introduction, there was no legal trade union for Korean civil servants and absence of such route or precedent for reacting against perceived negative impacts meant that:

[As they became increasingly] aware of the potential negative impacts of P4P, they figured out a solution to avoid them. The redistribution could let them manage the situation quietly without provoking problems... (P17: Senior Civil Service, started from Grade 5).

Thus $1 / \mathrm{n}$ was seen as being more in tune with core values of the service and responses were not perceived as parochialism or a short-term defense. The response was rooted in collectivist belief of familial-type relationships, and mutual cooperation 
as a key virtue. P4P with its assumptions of competitive individualism had the potential to create disharmony in these relationships amongst members:

We all do our best to accomplish the given tasks. So how can you make a ranking... The tasks of a regional office are relatively simple; mainly implementation of a policy. Given the circumstances, appraisals are unacceptable if we consider our traditional perspective ... we face each other every day. I am not confident that I am superior to others, or that colleagues are less productive. So we reached the conclusion that redistributing equally is the best solution (P12: lower ranked staff, started from Grade 9).

All lower ranked staff interviewees had participated in the practice, except two respondents who had 'team-based' P4P. As the team (bureau)-based P4P provided the same amount of rewards within a bureau, it had a similar logic to $1 / \mathrm{n}$ practice, so the civil servants involved had little need to embrace 1/n. Explanations for participation by lower ranked staff in $1 / \mathrm{n}$ included the sub-cultural context of a stronger sense of comradeship and continued adherence to traditional values of collectivism that exist amongst lower ranked staff.

By contrast, higher and middle ranking officials showed less enthusiasm towards this practice. None of the Senior Civil Service, and only a minority of division directors, participated in the practice and, given their managerial status, they perceived an obligation to follow official policy. Senior Civil Service viewed $1 / \mathrm{n}$ as problematic because it made it difficult to distinguish high and low performers. So why did some division directors originally participate in $1 / \mathrm{n}$ but not others? The answer lies in those participants having risen up the hierarchy, occupied distinct social roles, and during that rise having worked together with older 'non-elite' colleagues, who emphasised traditional collective values. Thus, they felt obliged to participate within a workplace atmosphere focussed on relationships, where highlighting individual performance was considered distasteful and civil servants did not wish to stand out amongst colleagues. Those who joined the civil service before 2000 were also more likely to have participated in the $1 / \mathrm{n}$ practice.

There was a spatial distribution of differential interests and attitudes. Those who worked in regional branches were more likely to participate than those in headquarters. Regional office employees identified strong beliefs supporting $1 / \mathrm{n}$ : namely, colleagues are familylike and all jobs equal in terms of importance and responsibility. There was also a worklocation structural context - in regional offices with relatively few staff, there was greater pressure to maintain personal relationships than in headquarters, where a larger group of employees lacked personal relationships. Interestingly, one lower ranked staff member who led the $1 / \mathrm{n}$ practice at his regional branch changed views on the acceptability of $1 / \mathrm{n}$ when he subsequently worked at headquarters where the prevailing sub-culture differed.

What does this experience of $1 / \mathrm{n}$ add to the understanding of "productive resistance? Does it for example support Piderit's (2000, 783, 785) suggestion that potentially positive intentions may be behind 'negative' responses? In the case reported so far, emergence of $1 / \mathrm{n}$ was underpinned by a desire to safeguard the organisational fabric - a collective identity premised on strong networks of relations and reciprocity. Whilst the example shares some similarities with instances whereby professional resistance emerges from change fatigue (e.g. Greasley et al. 2009; Clement 2014) this was not 
the major driver of the $1 / \mathrm{n}$ response. As a form of organisation-based resistance $1 / \mathrm{n}$ illustrates a clash between new systems of P4P and existing organisational structures and cultures. It is a threat to more established social relations - within which workbased identity is situated (also, O'Toole 1995; van Dijk and van Dick 2009, 144).

The response is productive when viewed from the vantage of securing support for existing organisational values but the response was not one offering clear 'counter proposals' by resistant subjects. Drawing upon the motivations and responses of the 'resistance process' (van Dijk and van Dick 2009, 144), illustrate how resisting 'the cultural colonisation of their identities' (see, Fleming and Spicer 2003) may result in a very distinct collective response, influenced by traditional values, and that here was unique to Korea. There should be caution therefore in defining productive resistance in a way that is overly Anglo-centric and which makes assumptions about motive and intention. The comments of Fronda $(2008,603)$ around 'cultural resistance' are particularly relevant whereby:

We mean here that people were attached to a symbolic set of terms of reference, or to "values", causing them [to] refuse "as best they can" the announced predominance of another symbolic reference, of other values, stemming from a political philosophy and society choices which are specifically Anglo-Saxon.

\section{2) Development and decline of $1 / \mathrm{n}$ practice}

The practice of $1 / \mathrm{n}$ was most pervasive in 2001 when the performance bonus was first distributed. However the practice had several manifestations and these evolved over time: redistribution whereby equal amounts went to each division or bureau employee; equal net distribution (following deduction of taxes); and redistribution that narrowed the gap between high and low P4P grades. At first, rewards were distributed equally and employees combined and then divided bonuses amongst employees in the division or bureau. There was a change to net rather than gross distribution because under the first method those initially awarded larger bonuses received lower rewards in the final distribution due to income tax deductions compared with colleagues deemed low performers! Thirdly, emerging disputes over redistribution practices amongst employees led to new distributions which sought to narrow the gap between high and low P4P graders, instead of distributing identical amounts.

The practice had mostly disappeared in central government by 2008 , although a regional branch where lower ranked staff worked still operated the practice at this time. (By contrast, local government officials are still currently practicing ' $1 / \mathrm{n}$ ' and are criticised for continuing the practice). Most respondents believed there were good reasons for the practice in the early 2000 s but that it was no longer acceptable a decade later. Even respondents who had originally participated agreed the practice had since lost its justification. Why did the practice evolve and subsequently disappear from central government?

There are some exogenous considerations that contributed to deinstitutionalization of the $1 / \mathrm{n}$ practice. What was then the Civil Service Commission (CSC), responsible for establishing and overseeing performance policy, became aware of what they regarded as dysfunctional responses to $\mathrm{P} 4 \mathrm{P}$ and issued guidance for individual ministries to crack down on the practice (CSC 2001; 2002). For example, ministries were 
warned that the overall size of $\mathrm{P} 4 \mathrm{P}$ rewards would be reduced, if such a practice was observed in a ministry. Senior management and supervisors received political direction around the importance of implementing P4P. The possibility of Departments and Ministries undergoing audit and investigation might likely have contributed to the changed context. As a division director admitted:

A strong external warning from our government terminated the practice of $1 / n$. Without these warnings being issued, civil servants might be still engaged in the practice. I think that it disappeared because the authority officially prohibited the practice with the help of regulation (P3: division director, started from Grade 9).

However, civil servants had also harbored an instrumental distrust of the appraisal system used for determining rewards as well as a commitment to collectivist values. Respondents perceived rudimentary appraisal methods being used to determine changes in salary. The response of $1 / n$ informed the development of the P4P system, which, in turn, undermined $1 / \mathrm{n}$. Thus MOSPA continuously revised the system to reflect civil servants' concerns, complaints and reactions. There were changes to the appraisal system and the rewards architecture - 'productive' outcomes of the reaction to acknowledge the importance of how total rewards are valued within the local context and of ensuring P4P is applied fairly and consistently so employees view them as legitimate (McCarthy et al. 2008, 232).

Given the development of appraisal methods and changes in the perception of supervisors (CSC 2003, 2004) the results of performance management were perceived more favorably. A lower ranked staff member suggested:

When we practiced $1 / n$, the appraisal was not fair. However, now we have improved appraisals... we have 360 degree feedback appraisal from supervisors and peer groups. It makes a huge difference. I feel it has become much fairer (P12: lower ranked staff, started from Grade 9).

When P4P was first introduced, the difference in rewards between high and low P4P grades was relatively small, which many felt comfortable with redistributing. However MOSPA also enlarged the size of P4P rewards and as these became larger, many civil servants revised their views:

As the size increased, civil servants started showing greater commitment to the rewards... It is awkward to share £2,000-3,000 with others because it is beyond an amount for just dining together with drinks. In a division, some are winners and the others are losers; it has become more difficult to speak publicly of sharing or redistribution (P1: division director, started from Grade 5).

How did altering the P4P scheme (e.g. increasing rewards) sit within prevailing values and culture? Earlier we noted that Korean culture is broadly collectivist in outlook and unlikely to immediately embrace some public management reforms. The revision of P4P appeared to involve some intensification of incentives - the very thing that $1 / \mathrm{n}$ had opposed. So why did resistance soften rather than harden? Here a discontinuity should be acknowledged in the acceptance and taken-for-grantedness that earlier had recreated 
the cultural norms. 'Institutions are understood as models that provide substantive guides for practical action. Institutions are durable to the extent that these models are reinforced through socialization or interaction or legitimation while alternative scripts remain unimaginable' (Clemens and Cook 1999, 445). At this point it is necessary to invoke the precautionary principle raised earlier. To isolate culture change is relatively difficult and care should be taken to not overstep what the evidence - both study evidence and wider social science - tells us about culture change. Elsewhere scholars have pointed to the three-way distinction of attitudes, values and culture (Hudson et al. 2014) and this is a relevant analytical device here. Thus attitudes may have a significant degree of instability, influenced as they are by immediate surrounding socio-economic conditions. Culture, by contrast, relates to dominant traditional or religious beliefs (such Confucianism) that have moulded fundamental aspects of society. Societal values lie in between, representing resilient ideas regarding what is desirable in organisational or social contexts, but being far less abstract than culture (Hudson et al. 2014).

There are indications that Korean values are changing given it has experienced growing interdependence with Western values and traditions. Some facets of competitive individualism are mirrored in Korean society (including a rampant examination competition). In the private sector lifetime employment is no longer guaranteed and human resource management has changed from seniority-based to performance- and competency-based following the introduction of greater competition within organisations (Park 2001). Wider changes are also reported, including erosion of respect for seniors and elders (Kim 1996), and individual goals and aspirations becoming more difficult to overlook alongside wider group goals. A cohort effect is evident and the workforce born after 1980 are considered different in that they place growing emphasis on individual values due to the growing hegemony of Western culture globally. The authority of the public sector has also been assailed with the rapid expansion of the private sector during the 1990s. A shrinking government role provided opportunity to question the motivation of civil servants with challenges to the longstanding social hierarchy (also Park 2010, 203 for support).

Against this wider backdrop of value change it is possible to situate interviewee responses from the study. They point to a nascent individualism alongside mainstay organisational traditions and practices and perhaps this offers insight concerning the acceptance of P4P:

When we were young, if supervisors ordered [food], all the employees ordered the same food. ${ }^{1}$ However, these days, younger guys clearly show their own preference. Likewise, within our workplace, young civil servants tend to state their own opinion. They are a different generation from ours (P3: division director, started from Grade 9).

As Oliver (1992), 575) writes: 'New members with backgrounds and experiences that differ from existing members bring different interpretive frameworks and social definitions of behaviour to the organization that act to diminish consensus and unquestioning adherence to take-for-granted practices'.

\footnotetext{
${ }^{1}$ The order of ordering food also starts from supervisor to lower ranked staff.
} 
Some of those who were graded highly and seen as high performers wished to personalise their own achievements and so refrained from redistributing bonuses. They were, in effect, less sensitive to criticism of being self-interested. Conversely, the $1 / \mathrm{n}$ practice was now criticised for being unfair because it treated equally both hard working and less committed employees. One division director explained:

I would say the 'culture' has changed from a 'concession culture' to a 'competitive culture'... In particular, competition has increased within the same ranks with similar careers. Looking back on my experiences, I remember that I had started to give more attention to my appraisal after being promoted to division director. I thought about my relative competitiveness compared to other division directors in order to receive a higher grade. I felt pressured (P1: division director, started from Grade 5).

To this point the softening of support for $1 / \mathrm{n}$ is linked to MOSPA offering both sanction and better reward, the latter appealing to shifts in attitudes and values, including a growing acknowledgement of individualism.

Civil servants' reframing also contributed towards a decline of $1 / \mathrm{n}$ because over time civil servants participating in $1 / \mathrm{n}$ expressed unease and ambivalence around what they were doing - recognition that adopting an oppositional standpoint, when obedience was expected, created its own dilemmas irrespective of whether they were viewing the original policy or the revised one (with the latter incorporating changes to appraisal and reward differentials):

Civil servants have a duty of obedience and are supposed to comply with regulations. Well, the practice of $1 / n$ is resistance to the policy. From the point of view of the policy making department, it should be corrected. Therefore, the practice of $1 / n$ is considered as noncompliance and violation of regulations. Given that civil servants are in charge of policy and regulation, the fact that they did not comply with policy created huge discomfort and anxiety... (P22: division director, male, started from Grade 5).

The considerable uneasiness by civil servants in the adoption of $1 / \mathrm{n}$, is captured in the simple aphorism two wrongs don't make a right. Thus despite the perceived problems of P4P it was still a measure that carried central authority. The subversive identity that 'discreet resistance' entailed was reluctantly adopted by civil servants who acknowledged their enmeshment amongst a complex web of professional values, organisational and identity and interpersonal relationships. This reluctance did not disappear, and despite (productive) resistance having buttressed collective culture and helping to improve acceptability of appraisal does not fully account for the greater acceptance of P4P. The process of individuals/groups coming to terms with change was a combination of individuals' reframing of the issues, and outside intervention (Randall and Procter 2008, 688). Accommodating newly introduced value systems, such as those underpinning public management reform initiatives, may entail tensions with prevailing values. The resolution of these tensions is an ongoing process of interplay involving, on the one hand, a reframing of subjectivities and, on the other, 
enforcement by central political bodies. However, even as this reframing of subjectivities is underway more established values retain power to reassert themselves during this process and this is seen in the re-institutionalisation of values represented by the seniority-based appraisal system.

\section{3) Seniority-based appraisal}

Discussion is not some linear account of resistance to an externally-driven change or where collectivism is displaced by individualism. In the revised $\mathrm{P} 4 \mathrm{P}$ arrangements, alongside greater incentives there was also a further, paradoxical, result. P4P was not implemented in a way that mirrored NPM principles of talent and effort being more clearly linked to rewards. Instead there was development of seniority-based appraisal. A central tenet of Confucian thinking is hierarchy and this development of P4P points to the enduring strength of key values. Thus a linchpin of the revised P4P system was an appraisal system whose processes were hierarchical and conservative. Some respondents reported frustration with this seniority-based appraisal, and one Senior Civil Servant recruited from the private sector expressed surprise at the low level of individualism and competition within the P4P system. But despite these dissenting views there was no return to the $1 / \mathrm{n}$ response that existed earlier in the change. The $\mathrm{P} 4 \mathrm{P}$ that finally emerges is then a curious blend of individualism (incentives) and hierarchy (the appraisal system). As Haverman and Rao (1997: 1620) note an environment of multiple competing institutional mandates may lead to the emergence of hybrid forms that combine various properties.

\section{Conclusion}

The discussion is one of institutionalisation, deinstitutionalisation and reinstitutionalisation, and which encompasses political, functional and social dynamics (Oliver 1992). Political dynamics include the challenges facing the Korean economy, political mandate for change and NPM aspirations. Functional ones are changes to the rewards and appraisal system and the spatial location of workplaces. Whilst social dynamics include how employees' age, rank and recruitment method contribute to a weakening of socialisation. In detailing what gave rise to such a 'discreet' form of resistance and its changing shape the article focussed on the nuances of a multidimensional response (Piderit 2000). The account has pointed to the differences - across work-site, recruitment method, age - of those participating in $1 / \mathrm{n}$, questioning a prevailing assumption of a homogenous civil service values and frames. The pressures for deinstitutionalisation - whether functional, political or social - do not automatically lead to a breakdown of norms. Individual interviews identified how group and organisation context were crucial in making sense of the change, and qualitative data focuses attention on how reactions were initially perceived, and subsequently revised, as context shifted. At issue is how attitudes and values are evolving and reshaping, but also reasserting their identity across place and over time. The experience of $1 / \mathrm{n}$ was a peculiarly Confucian-influenced response to a change and something of a very modern Korean resolution. Potentially at least, $1 / \mathrm{n}$ exemplifies a number of 
ongoing transitions and tensions evident within the Korean civil service, for example manifest in how work-life balance and gender equality are addressed.

In terms of its understanding of productive resistance the article's conclusion is three-fold. First, given diverse cultural settings there are nuances in the definition of productive resistance and as presented here it is neither a simple reading of intention; nor is it a straightforward example of apathy. Rather it emerged from the complexity of organisational fabric and agency. Second, productive resistance must be seen as part of a process that does not simply reflect 'offer and counter-offer'. How and whether productive resistance becomes integrated in a final policy change may sometimes appear contradictory: 'Schemas may be more or less mutable; they may embody internal contradictions; or multiple schemas or institutional rules may be potentially relevant to a context for action' (Clemens and Cook 1999, 447). Thirdly, there will be differences within groups and collectives concerning commitment towards resistance. These differences may only be fully apparent when time has lapsed and interpretations of resistance - productive or otherwise - can be put forward by those analysing the change.

Open Access This article is distributed under the terms of the Creative Commons Attribution 4.0 International License (http://creativecommons.org/licenses/by/4.0/), which permits unrestricted use, distribution, and reproduction in any medium, provided you give appropriate credit to the original author(s) and the source, provide a link to the Creative Commons license, and indicate if changes were made.

\section{References}

Ackroyd, S., \& Thompson, P. (1999). Organizational misbehaviour. London: Sage.

Bell, S. (2002). Institutionalism: Old and New. In D. Woodward (Ed.), Government, Politics, Power and Policy in Australia (7th ed.). Melbourne: Longman.

Binci, D., Cerruti, C., \& Donnarumma, S. A. (2012). Resistance in HROs, setback or resource? Journal of Organizational Change Management, 25(6), 867-882.

Burnes, B. (2009). Managing change: a strategic approach to organisational dynamics (5th ed.). Essex: Prentice Hall/Financial Times.

Burnes, B. (2015). Understanding resistance to change - building on Coch and French. Journal of Change Management, 15(2), 92-116.

Campbell, C. (1996). The myth of social action. Cambridge: Cambridge University Press.

Carr, J. B., \& Brower, R. S. (2000). Principled opportunism: evidence form the organizational middle. Public Affairs Quarterly Spring, 24(1), 109-138.

Clemens, E. S., \& J. M. Cook, J. M. (1999). Politics and institutionalism: explaining durability and change. Annual Review of Sociology, 25, 441-466.

Clement, J. (2014). Managing mandated educational change. School Leadership and Management, 34(1), 3951.

Coch, L., \& French Jr., J. (1948). Overcoming resistance to change. Human Relations, 1, 512-532.

Courpasson, D., Dany, F., \& Clegg, S. (2012). Resisters at work: generating productive resistance in the workplace. Organization Science, 23(3), 801-819.

Creswell, J. (2007). Qualitative inquiry \& research design: choosing among five approaches. London: Sage Publications.

Cunningham, J. B., \& Kempling, J. S. (2009). Implementing change in public sector organisations. Management Decision, 47(2), 330-344.

Dacin, T. M., Goodstein, J., \& Scott, R. W. (2002). Institutional theory and institutional change: introduction to the special research forum. Academy of Management Journal, 45(1), 45-56.

de Jager, P. (2001). Resistance to change: a new view of an old problem. The Futurist, 35(3), 24-27.

Deal, T. E., \& Kennedy, A. A. (1982). Corporate cultures: the rites and rituals of corporate life. Harmondsworth: Penguin Books. 
Dent, E. B., \& Goldberg, S. G. (1999). "Resistance to change": a limiting perspective. The Journal of Applied Behavioural Science, 35(1), 25-41.

Denzin, N., \& Lincoln, Y. (2008). The landscape of qualitative research. London: Sage Publications.

Emirbeyer, M., \& Goodwin, J. (1994). Network analysis, culture, and the problem of agency. American Journal of Sociology, 99, 1411-1454.

Erwin, D. G., \& Garman, A. N. (2010). Resistance to organizational change: linking research and practice. Leadership \& Organization Development Journal, 31(1), 39-56.

Ferneley, E. H., \& Sobreperez, P. (2006). Resist, comply or workaround? An examination of different facets of user engagement with information systems. European Journal of Information Systems, 15, 345-356.

Fleming, P., \& Spicer, A. (2003). Working at a cynical distance: implications for power, subjectivity and resistance. Organization, 10(1), 157-179.

Flick, U. (1998). An introduction to qualitative research. London: Sage.

Ford, J. D., Ford, L. W., \& D'Amelio, A. (2008). Resistance to change: the rest of the story. Academy of Management Review, 33(2), 362-377.

Frederickson, H. G. (2002). Confucius and the moral basis of bureaucracy. Administration \& Society, 33(6), 610-628.

Fronda, Y., \& Moriceau, J-L. (2008). I am not your hero: change management and culture shocks in a public sector corporation. Journal of Organizational Change Management, 21(5), 589-609.

Greasley, K., Watson, P., \& Patel, S. (2009). The impact of organisational change on public sector employees implementing the UK Government's "back to work" programme. Employee Relations, 31(4), 382-397.

Harvey, W. (2011). Strategies for conducting elite interviews. Qualitative Research, 11(4), 431-444.

Haverman, H., \& Rao, H. (1997). Structuring a theory of moral sentiment: institutional and organizational coevolution in the early thrift industry. American Journal of Sociology, 102, 1606-1651.

Hofstede, G. (2001). Culture's consequences: comparing values, behaviors, institutions and organizations across nations (2nd ed.). Thousand Oaks: Sage Publications.

Hudson, J., Jo, N.-K., \& Keung, A. (2014). Culture and the politics of welfare: exploring societal values and social choices. Basingstoke: Palgrave.

Hughes, M. (2010). Managing change: a critical perspective. London: CIPD.

Im, T. (2003). Bureaucratic power and the NPM reforms in Korea. International Review of Public Administration, 8(1), 89-102.

Jenkins, W. I. (1978). Policy analysis: a political and organisational perspective. London: Martin Robertson.

Kim, C. (1996). The culture of Korean industry: an ethnography of Poongsan corporation. Tucson \& London: The University of Arizona Press.

Kim, T. (2009). Confucianism, Modernities and knowledge: China, South Korea and Japan. International Handbook of Comparative Education, Springer International Handbooks of Education, 22, 857-872.

Kim, Y. J. (2012). Ethnographer location and the politics of translation: researching one's own group in a host country. Qualitative Research, 12(2), 131-146.

Kim, H.-O., \& Hoppe-Graff, S. (2001). Mothers roles in traditional and modern Korean families: the consequences for parental practices and adolescent socialization. Asia Pacific Education Review, 2(1), 85-93.

Ko, S. (2002). Republic of Korea. In M. Zanko \& E. Elgar (Eds.), The Handbook of Human Resource Management Policies and Practices in Asia-Pacific Economy (pp. 368-440). Cheltenham: Edward Elgar Publishing Limited.

Kotter, J. P., \& Schlesinger, L. A. (1979). Choosing strategies for change. Harvard Business Review, 57(2), $106-114$.

Krantz, J. (1999). Comment on "challenging 'resistance to change". The Journal of Applied Behavioural Science, 35(1), 42-44.

Layder, D. (1994). Understanding social theory. London: Sage.

Lines, R. (2004). Influence of participation in strategic change: resistance, organizational commitment and change goal achievement. Journal of Change Management, 4(3), 193-215.

Linstead, S., Fulop, L., Lilley, S., et al. (2004). Management and organization: a critical text. New York: Palgrave Macmillan.

Lloyd, C. (1986). Explanations in social history. New York: Basil Blackwell.

Lukes, S. (1974). Power: a radical view. London: Macmillan Press.

McCarthy, D. J., Puffer, S. M., May, R. C., Ledgerwood, D. E., \& Stewart, W. H. (2008). Overcoming resistance to change in Russian organizations: the legacy of transactional leadership. Organizational Dynamics, 37(3), 221-235.

McDermott, A. M., Fitzgerald, L., \& Buchanan, D. A. (2013). Beyond acceptance and resistance: entrepreneurial change agency responses in policy implementation. British Journal of Management, 24, S93-S115. 
McKay, J., Marshall, P., Grainger, N., \& Hirschheim, R. (2012). Change implementers' resistance: considering power and resistance in IT implementation projects. 23rd Australasian Conference on Information Systems, 3-5 December, Geelong.

Mercer, J. (2006). The challenges of insider research in educational institutions: wielding a double-edged sword and resolving delicate dilemmas. Oxford Review of Education, 33(1), 1-17.

Meyer, J. W. (2007). Reflections on Institutional Theories of Organizations. In R. Greenwood, C. Oliver, R. Suddaby, R., K. Sahlin-Andersson (Eds.), The Handbook of Organizational Institutionalism. Thousand Oaks, California: Sage Publications.

Miles, M., \& Huberman, A. (1994). Qualitative data analysis. London: Sage Publications.

Morse, J. M., Barrett, M., Mayan, M., Olson, K., \& Spiers, J. (2008). Verification strategies for establishing reliability and validity in qualitative research. International Journal of Qualitative Methods, 1(2), 13-22.

Nielsen, K. (2001). Institutionalist approaches in the social sciences: typology, dialogue, and future challenges. Journal of Economic Issues, 35(2), 505-516.

Northouse, P. G. (2012). Leadership: theory and practice. Thousand Oaks: Sage Publications.

O'Toole, J. (1995). Leading change: overcoming the ideology of comfort and the tyranny of custom. San Francisco: Jossey-Bass.

Oliver, C. (1992). The antecedents of deinstitutionalization. Organization Studies, 13(4), 563-588.

Park, W. (2001). HRM in South Korea. In P. Budhwar \& Y. Debrah (Eds.), Human resource management in developing countries (pp. 83-115). London: Routledge.

Park, C-O., \& Joo, J. (2010). Control over the Korean bureaucracy: a review of the NPM civil service reforms under the Roo Mo-Hyun government. Review of Public Personnel Administration, 30(2), 189-210.

Patalano, R. (2011). Resistance to change: historical excursus and contemporary interpretations. Review of Political Economy, 23(2), 249-266.

Piderit, S. K. (2000). Rethinking resistance and recognizing ambivalence: a multi-dimensional view of attitudes toward an organizational change. Academy of Management Review, 25(4), 783-794.

Pietese, J. H., Caniëls, M. C. J., \& Homan, T. (2012). Professional discourse and resistance to change. Journal of Organizational Change Management, 25(6), 798-818.

Randall, J., \& Procter, S. (2008). Ambiguity and ambivalence: senior managers accounts of organizational change in a restructured government department. Journal of Organizational Change, 21(6), 686-700.

Richards, L. (2009). Handling qualitative data: a practical guide. London: Sage Publications.

Ritchie, J., \& Lewis, J. (2003). Qualitative research practice: a guide for social science students and researchers. London: Sage.

Ritchie, J., \& Spencer, L. (1993). Qualitative data analysis for applied policy research. In A. Bryman \& R. Burgess (Eds.), Analysing Qualitative Data (pp. 173-194). London: Routledge.

Sagong, I. (1993). Korea in the world economy. Washington DC: Institute for International Economics.

Sandelowski, M. (1999). Time and qualitative research. Research in Nursing \& Health, 22, 79-87.

Scott, W. R. (2001). Institutions and organizations (2nd ed.). Thousand Oaks: Sage.

Song, B. (1990). The rise of the Korean economy. Hong Kong: Oxford University Press.

Starr, K. (2011). Principals and the politics of resistance to change. Educational Management Administration Leadership, 39(6), 646-660.

Strickland, F. (1998). The dynamics of change: insights into organisational transition from the natural world. London: Routledge.

Sturdy, A., \& Grey, C. (2003). Beneath and beyond organizational change management: exploring alternatives. Organization, 10(4), 651-662.

Sung, S. (2003). Women reconciling paid and unpaid work in a Confucian welfare state: the case of South Korea. Social Policy \& Administration, 37, 342-360.

Taylor, J. (2011). The intimate insider: negotiating the ethics of friendship when doing insider research. Qualitative Research, 11(1), 3-22.

Thoenig, J-C. (2011). Institutional theories and public institutions: new agendas and appropriateness. In B.G. Peters \& J. Pierre (Eds.), The Handbook of Public Administration (pp. 169-179). London: Sage Publications.

Thomas, R., \& Hardy, C. (2011). Reframing resistance to organizational change. Scandinavian Journal of Management, 27, 322-331.

van Dijk, R., \& van Dick, R. (2009). Navigating organizational change: change leaders, employee resistance and work-based identities. Journal of Change Management, 9(2), 143-163.

Watson, G. (1971). Resistance to change. American Behavioral Scientist, 14(5), 745-766.

Yoon, B. (2001). The new public management: its applicability to administrative reform in Korea. Doctoral thesis: The University of Exeter. 


\section{In Korean}

Civil Service Commission. (2001). Plans for key tasks in 2001. Seoul: CSC.

Civil Service Commission. (2002). Plans for key tasks in 2002. Seoul: CSC.

Civil Service Commission. (2003). Plans for key tasks in 2003. Seoul: CSC.

Civil Service Commission. (2004). White paper for five-year HRM reforms in the Korean civil service. Seoul: CSC. Jung, S. (2007). The Koreans' cultural grammar. Seoul: Saenggakui Namu.

Kim, J. (2004). Personnel Management in Public Administration. Seoul: Bupmoonsa.

Dr. Sunghee Park has degrees from Seoul National University, and the University of York. He is a career civil servant, and was seconded to the 2014 Incheon Asian Games Organising Committee and is currently Division Director in the Ministry of Personnel Management.

Dr. Neil Lunt is Professor of Social Policy and Public Management, University of York. He has a longstanding interest in cross-national policy and delivery, particularly those focussed on East Asia and Oceania. 